\title{
Estimates of humpback whale abundance off Kauai, 1989 to 1993: evaluating biases associated with sampling the Hawaiian Islands breeding assemblage
}

\author{
Salvatore Cerchio* \\ Moss Landing Marine Laboratories, PO Box 450, Moss Landing, California 95039, USA
}

\begin{abstract}
Identification photographs of humpback whales Megaptera novaeangliae, collected off Kauai during the years 1989 to 1993, were used to estimate population abundance off the Hawaiian Islands, USA A total of 790 different individuals (988 different observations) were identified during the study. Several mark-recapture procedures were applied to the data using closed population models (Chapman's modified Petersen, weighted mean of the Petersen, Darroch's maximum likelihood estimator [MLE], and Chao's $M_{l}, M_{h}$ and $M_{h h}$ estimators) and an open population model (Fisher-Ford estimator). The majority of population estimates were between 2000 and 5000 animals, with broad and overlapping $95 \%$ confidence intervals. Inconsistencies in pair-wise Petersen estimates and poor fit to the Fisher-Ford model indicated that the population of individuals was not identical for each sampling occasion. As a primary example of this, it is suggested that individuals captured in 1992 had a lower probability of capture in other years examined. Possibly the greatest problems in estimating abundance of this population dealt with temporary emigration and non-random mixing of the population between sampling occasions. After considering the range of estimates, and potential biases in the data set. I suggest that the abundance of humpback whales off the Hawaiian Islands is likely close to 4000 individuals, and most probably between 3000 and 5000. These estimates are considerably greater than those generated in the late 1970s and early 1980s and, if accurate, would indicate growth of the population over the past decade; however, it is strongly recommended that more representative and precise estimates be obtained for management purposes.
\end{abstract}

KEY WORDS: Humpback whale Mark-recapture Photographic identification A Abundance estimation

\section{INTRODUCTION}

Humpback whales Megaptera novaeangliae migrate annually between high latitude feeding areas and low latitude breeding areas. In the North Pacific, the primary known feeding areas are located along the Alaskan and central North American coasts (Baker et al. 1986, Calambokidis et al. 1990, 1993, 1996. Straley $1990,1994)$. The 3 primary breeding areas are (1) off

- Present address: Department of Biology and Museum of Zoology, University of Michigan, 1109 Geddes Ave., Ann Arbor, Michigan 48109-1079, USA. E-mail: sal@umich.edu the mainland coast of Mexico and the Islas Revillagigedos (Urbán \& Aguayo 1987, Alvarez et al. 1990), (2) off the main Hawaiian islands (Baker \& Herman 1981, Darling \& McSweeny 1985, Baker et al. 1986), and (3) off the Ryukyu and Bonin Islands south of Japan (Darling \& Mori 1993). The North Pacific population was severely depleted in the first half of the 20th century by commercial whaling (Rice 1974, 1978). Aerial and vessel surveys conducted of the Hawaiian Islands between 1976 and 1979 estimated abundance from 200 to 650 individuals, with upper $95 \%$ confidence limits as high as 790 individuals (Herman \& Antinoja 1977, Wolman \& Jurasz 1977, Rice \& Wolman 
$1978,1979)$. The results of subsequent studies, using mark-recapture techniques (Darling \& Morowitz 1986, Baker \& Herman 1987), raised questions regarding the validity of these early low estimates.

Individual humpback whales are identified by photographs of the pigmentation pattern on the underside of the flukes (Katona et al. 1979). Photographic identification has been applied to mark-recapture models to estimate population abundance of humpback whales in the North Pacific (Darling et al. 1983, Baker et al. 1986, Darling \& Morowitz 1986, Baker \& Herman 1987. Alvarez et al. 1990, Calambokidis et al. 1990, Perry et al. 1990) and in the North Atlantic (see Katona \& Beard 1990 for review). Use of mark-recapture models for biologists is presented in Otis et al. (1978), Begon (1979), Pollock et al. (1990) and Pollock (1991), whereas rigorous statistical treatment of these models is found in Otis et al. (1978) and Seber (1982). Hammond (1986) reviewed the application of mark-recapture models, with associated problems, specifically in relation to photographic identification data of cetaceans.

Estimates of humpback whale abundance off the Hawaiian Islands have been made using a variety of mark-recapture analyses. Darling et al. (1983), using samples collected off Maui in 1978 and 1979, estimated 895 whales (95\% confidence limits of 592 to 1837 ) using Bailey's modified Petersen estimator. After 2 additional years of data collection off Maui, Darling \& Morowitz (1986) increased their sample size to 1553 observations of 922 whales during 5 winters (1977 to 1981), and used the rate of discovery of previously unidentified individuals and a form of the Bernoulli distribution to estimate abundance. They estimated 1000 whales present during a single winter and 2100 whales during 5 winters (no confidence intervals were reported). Due to the difference between the single and multiple year estimates, Darling \& Morowitz (1986) suggested the population off Maui was not identical from year to year, and cited evidence that some whales visited different breeding areas in different years as a potential explanation. Switching of breeding areas by humpback whales has been documented in the southern hemisphere (Chittleborough 1965, Dawbin 1966), between Hawaii and Mexico (Darling \& Jurasz 1983, Darling \& McSweeney 1985, Baker et al. 1986), and most recently between Hawaii and Japan (Darling \& Cerchio 1993).

Baker \& Herman (1987) presented mark-recapture estimates using a sample of 519 individuals collected during 4 winters, 1980 to 1983 (the region sampled within Hawaiian waters was not reported). The unbiased Petersen estimator, applied to pairs of years, yielded estimates of 975 to 1923 whales, with overlapping $95 \%$ confidence intervals; the weighted mean of the Petersen yielded 1407 whales, with $95 \%$ confi- dence limits of 1113 to 1701; and the Jolly-Seber open model yielded estimates of 1044 and 635 whales, with overlapping $95 \%$ confidence intervals. Baker \& Herman (1987) concluded that the 'most robust' estimate was probably the weighted mean of the Petersen (1407 animals) because it had narrow confidence limits and used data from all years. However, they suggest this estimate may be positively biased due to violation of the assumption of population closure (i.e. due to births and deaths). Baker et al. (1986) reported a similar estimate using the weighted mean of the Petersen of 1627 whales, with $95 \%$ confidence limits of 1320 to 1934 , during 7 winters (1977 to 1983).

There have been no published studies of population abundance off the Hawaiian Islands since the early 1980 s data sets. This study estimated the abundance of humpback whales off the Hawaiian Islands using photographic mark-recapture data collected off Kauai during 1989 to 1993. Results of various models were used to evaluate problems associated with estimating the abundance of this wide-ranging population using data collected off a single island.

\section{METHODS}

Individual identification. Identification photographs of individual humpback whales were collected off Kauai during approximately mid-January to mid/lateApril in 1989 to 1993 . Kauai is the most north-western Hawaiian island, located at $22^{\circ} 05^{\prime} \mathrm{N}$ and $159^{\circ} 30^{\prime} \mathrm{W}$ The study area was off the south and west coasts in 1989 through 1993 as well as off the north coast in 1993 (Fig 1). During 1989 and 1990, 1 boat was used on a daily basis, weather permitting, and effort was divided between taking photographs and recording singing whales. During 1991, 1992, and 1993, 2 boats were used and photographic identification effort was increased. Photographs were taken with 400 ASA black and white film using $35 \mathrm{~mm}$ SLR cameras with 200 to $300 \mathrm{~mm}$ lenses, and $5.8 \times 8.4 \mathrm{~cm}$ prints were made of all good photographs.

An observation (capture) was defined as the identification of an individual on a given day, regardless of how many photographs of that whale were taken during the day. Photographs were compared within and among years to determine the total number of different observations, individual whales identified, and repeat observations (recaptures). With the addition of each year's data, the entire catalogue of photographs was reviewed, allowing multiple searches for matches. Photographs were graded good, fair, or poor on the basis of photographic quality, regardless of distinctiveness of the flukes. Aspects of photographs considered were focus, grain size of image, lighting, horizontal 
and vertical angle of flukes, and percentage of flukes visible. Photographs judged to be of poor quality, due to any of these considerations, were excluded from mark-recapture analyses. This reduced the potential for heterogeneity due to inclusion of poor quality distinctive flukes, and reduced the potential for missing marks and the associated positive bias (Hammond 1986). Several confirmed recaptures of very distinctive flukes were excluded from analysis on this basis.

On some occasions a good quality photograph was obtained of only the left or right tail fluke. Either of these could be compared to whole flukes but not to each other, so at least 1 group had to be excluded. Photographs of the right flukes were more abundant and of better average quality, so photographs of left flukes were excluded. Identifications of calves also were excluded from analyses due to the tendency for fluke patterns to change during the first year of life (Carlson et al. 1990).

Mark-recapture - closed population models. Abundance estimates were generated from several markrecapture models that assume a closed population, with each year's data representing a single sample. Detailed descriptions of models and assumptions can be found in Otis et al. (1978), Begon (1979), Seber (1982), Hammond (1986) and Pollock et al. (1990). Chapman's modified Petersen estimator for sampling without replacement (Hammond 1986) was used to estimate abundance for pairs of all years. Calambokidis et al. (1990) recommended the use of Chapman's model over Bailey's model (with replacement) due to potential negative bias introduced by sampling with replacement. It is highly likely that multiple captures of an individual within a year are not independent, introducing heterogeneity and negatively biasing abundance estimation. Estimates generated by Bailey's model with this data set were consistently lower than estimates using Chapman's model for the same years, as would be expected if sampling with replacement introduced heterogeneity. Chapman's model, therefore, is likely more accurate.

Five other closed models used multiple samples: the weighted mean of the Petersen (Begon 1979, the Schnabel estimator in Seber 1982), Darroch's maximum likelihood estimator (MLE) for capture probabilities that vary with time (Darroch 1958, modified by Otis et al. 1978), and Chao's models for capture proba- bilities that vary with time (Chao 1989), individual (heterogeneity; Chao 1989), and time in combination with individual (Chao et al. 1992). The 4 latter models were estimated using the program CAPTURE (Otis et al. 1978), which is distributed by the Colorado Cooperative Fish and Wildlife Research Unit. The models in CAPTURE were designed to relax the assumption of equal probability of capture among individuals in 1 or more of 3 ways: due to heterogeneity (model $M_{h}$ ), variation among sampling occasions (model $\mathrm{M}_{\mathrm{t}}$ ), and behavioral response to capture (model $\mathrm{M}_{\mathrm{b}}$ ). The estimators are complex numerical functions without simple 'open form' solutions, and readers are directed to the original literature for descriptions of their mechanics. The program CAPTURE also allows tests for closure and appropriate model, including tests for heterogeneity and variation of capture probability with time. The test for closure assumes a null hypothesis that capture probability for a given individual $\left(p_{1}\right)$ is the same at each sampling occasion. This is tested against an alternative hypothesis that for some individuals, $p_{1}=0$ at either the beginning and/or the end of the study. Only individuals captured 2 or more times are considered. The tests for heterogeneity and variation of capture probability with time fit the observed distribution of capture frequencies to that expected for a population with equal catchabilities (the null Model, $M_{0}$ ). The chi-squared statistic is used to test for significant deviation from expected values. Goodness of fit tests are 
then used to test the fit of the data to the various models $\left(M_{h}, M_{t}\right.$, and $M_{b}$ ). Based upon the results of these tests, CAPTURE recommends the most appropriate model for the data. In this analysis, I used the recommended model, as well as similar models provided in the package, to evaluate the effect of different sets of assumptions on abundance estimation.

Open population models. I evaluated the use of 2 models that assume an open population, the JollySeber model (Begon 1979, Hammond 1986, 1987, Pollock et al, 1990) and the Fisher-Ford model (Fisher \& Ford 1947, Begon 1979). Calambokidis et al. (1990) and Straley $(1990,1994)$ used the Jolly-Seber model to estimate humpback whale abundance with varying degrees of success. Each of these data sets were characterized by high capture probabilities and abundant recaptures, and Jolly-Seber yielded consistent results. Conversely, it has been shown that Jolly-Seber consistently overestimates abundance $(N)$ when capture probability is low $(\mathrm{p}<0.09)$ and few recaptures are available, and that Fisher-Ford is preferable when constant survival rates can be assumed (Manly 1970 , Bishop \& Sheppard 1973, Begon 1979). With this data set, Jolly-Seber yielded highly variable, imprecise and unrealistic results likely due to a low capture probability and sparse recaptures. These results indicated that sampling in this study was not adequate for JollySeber, and Fisher-Ford was preferable. Therefore I report only the results of the Fisher-Ford model.

The Fisher-Ford model previously has not been applied to photographic identification data of cetaceans, so the method will be briefly described (see also Fisher \& Ford 1947, and Begon 1979, p. 27). The model makes the same assumptions as Jolly-Seber with the addition that survival rate $(\phi)$ is constant throughout the samples. In contrast to most other models, the Fisher-Ford method is concerned with marks, and specifically age of marks, as opposed to individuals. For example, if an individual is captured (photographed) in 3 samples, in the third sample it is counted as 2 marks of different ages. Like the JollySeber model, Fisher-Ford assumes recruitment and loss (including loss of marked individuals), and seeks to estimate the number of marks at risk of capture in the population $\left(M_{i}\right)$ on each sampling occasion, $i$. The first step is to sum the total time survived by all recaptured marks, in this case the total years survived (observed TYS). Next, the average age of marks in the population $\left(A_{1}\right)$ is estimated for each sampling occasion (i) in an indirect manner. $A_{i}$ is dependent on the survival $(\phi)$ of marked individuals and the proportion of older to younger marks comprising $M_{1}$. Since $\phi$ is assumed constant, any given $\hat{\phi}$ will yield a corresponding set of $\hat{A}_{1}$. By multiplying $\hat{A}_{1}$ by number of recaptures $\left(m_{i}\right)$, the expected total age of recaptured marks is esti- mated for each year, $i$, which can then be compared to the actual observed total age. By summing among years, an expected TYS $\left(\Sigma_{1} \hat{A}_{1} m_{1}\right)$ is obtained. Finally, $\hat{\phi}$ is varied until the expected TYS matches the observed TYS. In this reiterative manner, one determines a constant $\hat{\phi}_{1}$ each $\hat{A}_{1}$ and each $\hat{M}_{1}$. The resulting $\hat{M}_{1}$ values are then used to estimate abundance $\left(\hat{N}_{i}\right)$, using Bailey's unbiased Petersen estimator. A disadvantage of the Fisher-Ford model is the lack of a calculation for confidence intervals, and therefore no measure of precision. An advantage is the ability to examine the assumption of constant survival rate for each year by comparing expected TYS with the observed TYS using a $\chi^{2}$ test (Begon 1979, p. 59).

\section{RESULTS}

\section{Sample}

A total of 988 observations of 790 different individuals were made during the 5 years (Table 1). An additional 19 observations of left-half flukes were excluded from analysis (the complete flukes of 2 of these individuals were photographed on other occasions, and one 1990 to 1991 recapture was excluded as a result). Yearly sample sizes ranged from 86 observations of 80 individuals in 1989, to 289 observations of 246 individuals in 1993. The largest samples were obtained in the last 3 years, primarily due to increased effort. Numbers of recaptures increased each year corresponding to increased sample sizes and marks at risk. Within-year capture frequencies were relatively low, with most individuals being captured on only $1 \mathrm{~d}$ and very few on

Table 1. Megaptera novaengliae. Samples and recaptures of humpback whales off Kauai in 1989 to 1993 . Sample size $\left(n_{i}\right)$ is expressed as number of different individuals and number of unique observations each year (individuals were given 1 observation each day sighted, regardless of the number of pods in which they were photographed). Recaptures $\left(m_{1}\right)$ are expressed as the total number of individuals that were sighted from a previous year $(j)$. For recapture values in parentheses, individuals recaptured in multiple years were counted for only the most recent previous year sighted; summation of these values results in the total number of individuals recaptured in a year (Total $m_{1}$ )

\begin{tabular}{|c|c|c|c|c|c|c|c|}
\hline \multirow{2}{*}{$\begin{array}{l}\text { Year } \\
\text { (i) }\end{array}$} & \multicolumn{2}{|c|}{$n_{1}$} & \multicolumn{4}{|c|}{ Total recaptures $\left(m_{I J}\right)$} & \multirow{2}{*}{$\begin{array}{c}\text { Total } \\
m_{1}\end{array}$} \\
\hline & Ind. & Obs & 1989 & 1990 & 1991 & 1992 & \\
\hline 1989 & 80 & 86 & - & & & & \\
\hline 1990 & 91 & 96 & $4(4)$ & - & & & 4 \\
\hline 1991 & 198 & 228 & $3(2)$ & $4(4)$ & - & & 6 \\
\hline 1992 & 244 & 289 & $7(5)$ & $4(3)$ & $11(11)$ & - & 19 \\
\hline 1993 & 24.6 & 289 & $7(7)$ & $7(5)$ & $18(17)$ & $11(11)$ & 40 \\
\hline Total & 790 & 988 & & & & & \\
\hline
\end{tabular}


Table 2. Megaptera novaengliae. Frequency of capture of humpback whales off Kauai from 1989 to 1993. (a) Number of individuals with each sighting frequency (number of days each whale was captured) is indicated for within-year recaptures, along with average intervals between first and last capture. (b) Across-year sighting frequencies (number of years each whale was captured) consider only whether an individual was captured in any year

\begin{tabular}{|c|c|c|c|c|}
\hline \multirow[t]{2}{*}{ (a) Within-year } & \multicolumn{4}{|c|}{ Number of days captured } \\
\hline & 1 & 2 & 3 & 4 \\
\hline 1989 & 76 & 2 & 2 & 0 \\
\hline 1990 & 86 & 5 & 0 & 0 \\
\hline 1991 & 172 & 23 & 2 & 1 \\
\hline 1992 & 210 & 24 & 9 & 1 \\
\hline 1993 & 211 & 28 & 6 & 1 \\
\hline Mean days ${ }^{a}$ & - & 15 & 23 & 37 \\
\hline SD days ${ }^{2}$ & - & 16.0 & 12.3 & 19.1 \\
\hline \multirow[t]{2}{*}{ (b) Across-year } & \multicolumn{4}{|c|}{ Number of years captured } \\
\hline & 1 & 2 & 3 & 4 \\
\hline $1989-1993$ & 727 & 58 & 4 & 1 \\
\hline Mean number b & weer & and 1 & pture & \\
\hline
\end{tabular}

more than 2 d (Table 2a). Probability of within-year recapture varied among years, with $5 \%$ of individuals captured on more than one day in 1989 and 1990, 13\% in 1991, and $14 \%$ in 1992 and 1993. The increase in recapture probability in the latter 3 years was likely due to greater effort and doubling of sample size. Similarly, across-year capture frequencies were also low, with most individuals (727) being captured in only $1 \mathrm{yr}$, and few (5) in more than 2 yr (Table 2 b). Only $8 \%$ of all individuals were captured in more than $1 \mathrm{yr}$.

\section{Closed population models}

Abundance estimates from pair-wise Chapman's Petersen comparisons ranged from 1489 to 5042 individuals with relatively poor precision, coefficients of variation (CV) ranging from 0.20 to 0.43 (Table 3). Of the 4 largest estimates (in excess of 4000), 3 used 1992 as either the capture or recapture year. This may hold significant implications as discussed below. The weighted mean of the Petersen, making use of all years' data, yielded an intermediate estimate of 3880 with greater precision $195 \%$ confidence limits of 2958 and 4802 and a CV of 0.12 ).
A test for closure using the program CAPTURE indicated that the assumption was not violated $(z=1.278$, $p>0.1$ ). Otis et al. (1978) stated that this test is designed to detect the breakdown of closure (i.e. $p_{1}=0$ ) at the beginning or end of the study and, therefore, is not sensitive to temporary emigration. Furthermore, the power of this test is questionable with low numbers of recaptures. Tests for heterogeneity and variation with time indicated that capture probability likely varied with individual $\left(\chi_{1}^{2}=4.737, \mathrm{p}=0.03\right)$, and sampling occasion $\left(\chi_{4}^{2}=186.626, p<0.001\right)$. The goodness of fit test for model $M_{h}$ rejected the null hypothesis that individual capture probabilities $\left(p_{l}\right)$ varied among individuals but not with time $\left(\chi_{4}^{2}=160.541, p<0.001\right)$. The goodness of fit test for model $M_{1}$ rejected the null hypothesis that probability of capture on each sampling occasion $\left(p_{j}\right)$ varied with sample but was constant among individuals $\left(\chi_{165}^{2}=203.659 p=0.02\right)$. Given the test results, it appears that model $M_{\mathrm{th}}$ was the most appropriate model; however, these tests for assumptions are not always reliable with sparse data (Chao 1989, K. Burnham pers, comm.).

Population estimates from CAPTURE were generated using models $M_{h}, M_{t}$, and $M_{t h}$ in order to compare among results (Table 3). Chao's $M_{h}$ generated the highest estimate of 5346 , with $95 \%$ confidence limits of 4181 and 6911 (CV of 0.13). Darroch's M and Chao's

Table 3. Megaptera novaengliae. Population abundance estimates from closed mark-recapture models. The final 4 models were generated by the program CAPTURE (Otis et al. 1978). SE: standard error; CV: coefficient of variation; CI: confidence interval. See text for definition of variables

\begin{tabular}{|c|c|c|c|c|c|c|c|}
\hline Year & $n_{1}$ & $n_{2}$ & $m_{2}$ & $\hat{N}$ & $\mathrm{SE}$ & $\mathrm{CV}$ & $95 \% \mathrm{CI}$ \\
\hline \multicolumn{8}{|c|}{ Chapman's modified Petersen (without replacement) } \\
\hline $89-90$ & 80 & 91 & 4 & 1489 & 573.1 & 0.38 & $366-2612$ \\
\hline $89-91$ & 80 & 198 & 3 & 4029 & 1739.3 & 0.43 & $620-7438$ \\
\hline $90-91$ & 91 & 198 & 4 & 3661 & 1435.3 & 0.39 & $848-6474$ \\
\hline $89-92$ & 80 & 244 & 7 & 2480 & 772.1 & 0.31 & $967-3993$ \\
\hline $90-92$ & 91 & 244 & 4 & 4507 & 1771.3 & 0.39 & $1035-7979$ \\
\hline $91-92$ & 198 & 244 & 11 & 4062 & 1065.3 & 0.26 & $1974-6150$ \\
\hline $89-93$ & 80 & 246 & 7 & 2500 & 778.5 & 0.31 & $974-4026$ \\
\hline $90-93$ & 91 & 246 & 7 & 2840 & 890.0 & 0.31 & $1096-4584$ \\
\hline $91-93$ & 198 & 246 & 18 & 2586 & 528.6 & 0.20 & $1550-3622$ \\
\hline $92-93$ & 244 & 246 & 11 & 5042 & 1330.4 & 0.26 & $2434-7650$ \\
\hline \multicolumn{8}{|c|}{ Weighted mean of the Petersen } \\
\hline 89 to 93 & & & & 3880 & 470.6 & 0.12 & $2958-4802$ \\
\hline \multicolumn{8}{|c|}{ Chao $M_{h}$ - capture probability varies with individual (heterogeneity) } \\
\hline 89 to 93 & & & & 5346 & 690.4 & 0.13 & $4181-6911$ \\
\hline \multicolumn{8}{|c|}{ Darroch $M_{1}$-capture probability varies with time } \\
\hline 89 to 93 & & & & 3959 & 438.7 & 0.11 & $3208-4941$ \\
\hline \multicolumn{8}{|c|}{ Chao $M_{t}$-capture probability varies with time } \\
\hline 89 to 93 & & & & 4196 & 514.4 & 0.12 & $3328-5362$ \\
\hline \multicolumn{8}{|c|}{ Chao $\mathrm{M}_{\mathrm{th}}$ - capture probability varies with time and individual } \\
\hline 89 to 93 & & & & 4858 & 684.5 & 0.14 & $3722-6434$ \\
\hline
\end{tabular}


$M_{1}$ estimates were similar at 3959 and 4196, respectively, with similar confidence intervals (CVs of 0.11 and 0.12 ). Chao's $M_{\mathrm{th}}$ generated an intermediate estimate of 4858 , with the proportionally largest confidence interval from 3722 to 6434 (CV of 0.14 ).

\section{Open population models}

The Fisher-Ford model was calculated using 2 survival rate estimates (Table 4). In order to match the expected TYS to observed TYS, an estimated survival rate of 1.206 was required. This yielded 1991 to 1993 abundance estimates in excess of 5000 animals (Table $4 \mathrm{a}$ ). The positively biased survival rate is unrealistic and results in $\hat{M}_{1}$ greater than the number of animals known to be marked in each year. A survival rate greater than 1.0, essentially a positive loss, does not indicate a gain; rather it is likely a survival rate very close to 1.0 combined with a positive sampling error (Begon 1979). Therefore, the model was generated again with a realistic survival rate of 0.951 (Table $4 \mathrm{~b}$ ), the rate estimated by Buckland (1990) for a North Atlantic population of humpback whales. As with the Petersen models, the smallest estimate is generated by the 1989 to 1990 data, 1400. Estimates from the remaining years were above 3000 animals, with the 1993 estimate (using all data) at 3115 animals. Chisquared tests for differences between observed and expected TYS values indicated that the assumption of a constant survival rate was not violated $\left(\chi_{3}^{2}=0.037, p>\right.$
0.99 , for $\hat{\phi}=1.206 ; \chi_{3}^{2}=2.037, \mathrm{p}=0.57$, for $\hat{\phi}=0.951$ ). A weakness of the Fisher-Ford model is the inability to estimate variance; therefore, it was impossible to judge the precision of these estimates.

\section{DISCUSSION}

Several problems with these data must be considered in order to evaluate the validity of the estimates. Considering this study spanned 5 yr, there was a lack of closure due to births and deaths, and probably temporary emigration. Probability of capture varied over time due to differences in sampling effort among years. Heterogeneity was likely present, as in many studies of free-ranging cetaceans (Hammond 1990). Probability of capture may have varied among individuals and time in a non-random manner due to movement palterns of animals throughout the Hawaiian Islands, which may result in a situation similar to temporary emigration. The estimates were reviewed in light of these points with particular attention given to the latter.

\section{Closed population models}

Pair-wise Petersen estimates using adjacent years minimize bias due to lack of closure. Moreover, by excluding calves, the effects of recruitment due to birth are further minimized in adjacent year comparisons. When only death and emigration occur, 2-sample models yield valid estimates for the first sampling occasion (Begon 1979, Seber 1982). We, therefore, would expect pair-wise estimates from adjacent years to be least biased, and consequently smaller than estimates from samples separated by several years. The reverse occurred in this study, as illustrated by the 1992 to 1993 estimate of 5042 whales and the 1989 to 1993 estimate of 2500 whales (Table 3). Furthermore, despite large CVs and overlapping $95 \%$ confidence intervals, goodness-of-fit tests designed to compare pairs of estimates (Seber 1982, p. 121) suggested that population composition varied significantly among some samples. In 9 comparisons with the smallest estimate, 3 tests indicated significant differences between the sampled populations at an $\alpha$ of 0.05 , and an additional 3 at an $\alpha$ of 0.10 ; 
similarly, in 9 comparisons with the largest estimate, 3 were significant at an $\alpha$ of 0.05 and an additional 2 at an $\alpha$ of 0.10 . Therefore, variability among some of the point estimates may be due to factors other than random variation in sampling. Individual probability of capture apparently varied from year to year in a nonrandom manner. This will be discussed in detail below.

Closed models that use data from multiple years have the advantage of a larger sample size, and therefore greater accuracy and precision; however, they are more subject to the effects of closure violations. Hammond (1986) reported that in an extreme case, bias due to simultaneous loss and recruitment can be as high as $+11 \%$ over 1 yr and $+37 \%$ over 3 yr. The loss and gain values used by Hammond (1986; $\alpha=0.10$ and $\phi=0.90$ ) likely overestimated actual turnover rate for humpback whale populations (Buckland 1990). Therefore, while there is potential positive bias in these multipleyear closed estimates, it is probably not as severe as indicated by Hammond (1986). Failure of CAPTURE's closure test to reject the null hypothesis further suggests that turnover may not have been very high during this study, although, as stated previously, power was probably low due to scarcity of recaptures.

The weighted mean of the Petersen, Darroch's $M_{t}$ and Chao's $M_{1}$, all compensate for variation in capture probability with time, and all produce similar estimates (Table 3). Chao (1989), using computer simulations, showed that Darroch's model tends to overestimate $N$ with sparse data, and that her model is then more appropriate; however, if recaptures are relatively more abundant, Darroch's model performs better With this data set, Chao's model yielded an estimate greater than Darroch's, indicating that Chao's model may be most applicable to even sparser data (i.e. the Illinois mud turtle data set used in Chao 1989).

Chao (1989) also reported that her $M_{t}$ estimator, which assumes equal capture probabilities among individuals, underestimates $N$ in the presence of heterogeneity, as expected (Hammond 1986, 1990). Conversely, if there is no heterogeneity, models $\mathrm{Mh}_{\mathrm{h}}$ and $M_{\text {th }}$ will overestimate $N$ (Chao 1989, Chao et al. 1992). The magnitude of effect in either case depends upon the degree of heterogeneity, i.e. the difference between individuals with the smallest and greatest $p_{i}$. Potential sources of heterogeneity include individual differences in behavior (such as probability of showing flukes), geographic stratification in range of the population, and sex related biases in capture probability. Geographic stratification in range has been illustrated for the feeding assemblage off California (Calambokidis et al. 1993), but does not appear to be prevalent among the Hawaiian Islands in across-year comparisons (Cerchio et al. 1998, in this issue). There is likely a bias in capture probability by sex in breeding regions, with males being more likely captured (Gabriele 1992, Brown et al. 1995, Palsboll et al. 1997, Cerchio et al. 1998); Calambokidis et al. (1998) estimated a $10 \%$ bias for a skewed sex ratio of $2: 1$, and a $25 \%$ bias for an extreme skew of $3: 1$ with estimation models that do not correct for heterogeneity. The estimate of Chao's model $M_{1 \mathrm{~h}}$ is 16 to $25 \%$ greater than the $3 \mathrm{M}_{1}$ models, within the range of bias reported by Calambokidis et al. (1998)

The best choice among the closed models then becomes dependent on determination of heterogeneity. Tests of assumptions in CAPTURE indicated that probability of capture varied with both time and individual. These tests are not always reliable with low recaptures ( $\mathrm{K}$. Burnham pers. comm.), and they are sensitive to variation due to behavioral effects, such as trap effects (Otis et al. 1978). It is possible that the effects of temporary emigration may also influence these tests. Low capture probabilities and few multiple captures made it impossible to apply other tests of heterogeneity, such as used by Calambokidis et al. (1990) and Hammond (1990). It is, therefore, difficult to make a conclusive argument for or against heterogeneity. Considering the results of the CAPTURE tests on these data, and other studies indicating the presence of heterogeneity in humpback whale populations, model $\mathrm{M}_{\mathrm{th}}$ may well be the best choice. It should be reemphasized that the estimate derived from model $\mathrm{M}_{\mathrm{th}}$ is still likely positively biased due to closure violations.

\section{Open population models}

The Fisher-Ford model had difficulty matching the expected TYS to the observed TYS value (Table 4). Using a survival rate greater than 1.0 is obviously not satisfactory, and when a survival rate of 0.951 is used, the estimates from 1991 to 1993 are typically lower than results of the closed models. This reflects a correction for bias due to closure violation; however, these estimates are not corrected for heterogeneity and therefore may be negatively biased. Moreover, the discrepancy between observed and expected TYS values must be reconciled. Fisher \& Ford (1947) stated that differences between a given sample's observed and expected TYS values indicate a discrepancy between actual and estimated survival rates. When using an estimated survival rate of 0.951 , the observed survival of marks in 1992 and 1993 was greater than expected (compare the summation of the TYS and $\hat{A}_{i} m_{i}$ columns; Table $4 \mathrm{~b}$ ). Herein lies the strength of the Fisher-Ford model in evaluating the patterns of capture probabilities among different sample years. The model interprets these discrepancies as variations in survival rates; however, in this sample the differences are likely 
due to emigration and variation in capture probabilities of individuals among different sample years. This possibility will be explored in detail in the next section.

\section{Variation in probability of capture due to non-random movement}

The closed capture models used in this study were designed to allow for variation in capture probability with individual and/or sampling occasion (Otis et al. 1978, Chao 1989, Chao et al. 1992). However, difficulties arise when individual capture probabilities vary among sampling occasions in a manner that is nonrandom and inconsistent among individuals. Hammond (1986) discusses in detail problems associated with the assumption of 'equal probability of sighting when sampling a highly mobile population in a small portion of its range. If mixing throughout the entire range is uniform, then the absence (or low capture probability) of a random sample of the population during any sampling occasion does not introduce bias. This assumption was implicit in all studies that have sought to estimate abundance of whales off the Hawaiian Islands from a single area (Darling \& Morowitz 1986, Baker \& Herman 1987). If mixing is non-random, and certain individuals are consistently less likely to be captured, than heterogeneity is introduced and population estimates are negatively biased. Calambokidis et al. (1993) described this situation of the coast of California due to differences among individuals in their geographic ranges

Another type of non-random mixing would result if a subgroup of the population had individual capture probabilities that varied significantly with sampling occasion in a manner inconsistent with the rest of the population. An extreme case would be non-random temporary emigration, when a subgroup is absent $\left(p_{1}=0\right)$ for some, but not all, sampling occasions. Temporary emigration can result in overestimation of abundance, because models treat absent individuals as present but not captured (Begon 1979). Note that with low numbers of recaptures, it is difficult to distinguish between the absence of individuals (i.e. due to temporary emigration) and the presence of individuals with very low capture probabilities (i.e. due to short residency within the sample area). With very low capture probabilities, the effect is likely to be similar to temporary emigration.

There is evidence within this data set that non-random temporary emigration, or a similar situation, exists among humpback whales off the Hawaiian Islands. This becomes apparent when considering the pairwise Petersen estimates (Table 3). If we view the proportion of recaptures, and resultant abundance estimates, as an indication of 'relatedness' between pairs of samples, we find that some samples have more individuals in common (lower estimates) than others (higher estimates). As an example, and primary trend, 3 of 4 comparisons involving the 1992 sample produced the 3 highest estimates. This indicates that in 1992 there may have been a subgroup of individuals captured that had relatively lower capture probabilities in other years, particularly 1990, 1991 and 1993. In other words, a group of individuals may have immigrated to Kauai in 1992 and subsequently emigrated. This relationship is borne out with further consideration of the data

Begon (1979) suggested a test for equal catchability among recognizable subgroups in a population. The test assumes simply that the various subgroups will be recaptured in a proportion equivalent to the marks at risk, and uses a contingency table to test between observed and expected recaptures (and not-recaptures) among subgroups. This test was applied to the 1993 sample treating individuals captured in each of the previous years as 4 different subgroups (Table 5). It was assumed that survival rate approached 1.0 and did not substantially effect recaptures. The test could not reject equal probability of capture among the 1989 to 1992 animals $\left(\chi_{3}^{2}=4.092, \mathrm{p}=0.25\right)$; however, there were fewer than expected recaptures from 1992 and more than expected from 1991. When the 1992 sample is excluded, the fit to the observed data is much better $\left(\chi_{2}^{2}=0.155, \mathrm{p}=0.93\right)$, with expected recaptures nearly matching the observed. This suggests that at least some portion of individuals captured in 1992 may not

Table 5. Megaptera novaengliae. Test for equal catchability among humpback whales recaptured in 1993 from the 4 previous sample years. Contingency tables were used to test for differences between observed and expected recaptures from 1989 through 1992 (all years) and 1989 through 1991 (excluding 1992!

\begin{tabular}{|lccc|}
\hline \multirow{2}{*}{ Release year } & Observed & \multicolumn{2}{c|}{ Expected } \\
& & All years & Excl. 1992 \\
& & & \\
1989 & 7 & 5.6 & 6.9 \\
Recaptured & 73 & 74.4 & 73.1 \\
Not recaptured & & & \\
1990 & 7 & 6.4 & 7.9 \\
Recaptured & 84 & 84.6 & 83.1 \\
Not recaptured & & 13.9 & 17.2 \\
1991 & 18 & 184.1 & 180.8 \\
Recaptured & 180 & & \\
Not recaptured & & 17.1 & \\
1992 & 11 & 226.9 & \\
Recaptured & 233 & 4.092 & 0.155 \\
Not recaptured & & 3 & 2 \\
Chi squared & & 0.25 & 0.93 \\
df & & & \\
p & & & \\
\hline
\end{tabular}


have been equally represented in 1993.

Variation of capture probabilities in the 1992 sample can also explain the discrepancies in the Fisher-Ford model (Table 4 b). Recall that observed TYS is the summed ages of all recaptured marks in a sample. The effect of a constant survival rate is a decrease in expected recaptures of increasingly older marks. Estimated average age of marks at risk $\left(\hat{A}_{i}\right)$ is calculated assuming the constant survival rate and loss of older marks. Since the expected TYS is obtained by multiplying each $\hat{A}_{i}$ by recaptures from all previous years $\left(m_{1}\right)$, discrepancies between observed and expected values would result from a higher than expected number of 'old' recaptured marks, and/or a lower than expected number of 'young' recaptured marks. In 1992 the ratio of 1989 to 1991 marks was higher than expected, causing the observed TYS to exceed the expected TYS. In 1993, there were fewer than expected 1992 marks, again causing the observed TYS to exceed the expected TYS. This would result from the capture of individuals in 1992 that were less likely to be captured in previous years (at least in 1990 and 1991), and less likely to be captured in 1993.

Abundance estimates were recalculated excluding the 1992 sample to examine the effect of this variation in capture probabilities (Table 6). In the Fisher-Ford model, the expected and observed TYS values converged at a survival rate of 0.955 . The observed and expected TYS for each year agreed precisely, indicating a good fit to the model $\left(\chi_{2}^{2}=0.004, p>0.99\right)$. As expected, the population estimate for 1993 was substantially reduced; however, there was greater variation among the estimates. Interestingly, the estimated survival rate of 0.955 is in close agreement with a survival estimate of 0.951 ( $95 \%$ confidence limits of 0.929 , $0.969)$ reported for humpback whales in the North Atlantic (Buckland 1990). When the closed models are repeated without the 1992 sample, each estimate is also reduced by 500 to 750 animals. Precision is poorer, corresponding to the reduction in sample size.

We may conclude that an event of temporary immigration and emigration occurred in 1992, introducing a positive bias into the abundance estimates. However, excluding the 1992 sample would at the same time introduce heterogeneity. If, in fact, there was a subgroup of individuals present in 1992 that had lower probabilities of capture in other years, then by excluding the 1992 sample, this group is even less represented and the population of the Hawaiian Islands as a whole is underestimated. The effect of non-random variation in capture probabilities remains unknown without more information on the specific patterns of movement and migration.

The 1992 sample was used as an example to illustrate potential non-random mixing. In reality, the situation would not be as simple as a single subgroup visiting Kauai only in 1992. More generally, it appears that the population composition off Kauai varied from year to year. There are several possible explanations for such variation. Individuals or subgroups may spend the majority of their time off different islands in different years. Alternatively, exchange between breeding grounds among years may be greater than currently considered.

Movements of individually identified whales among the Hawaiian Islands have been documented in several studies (Baker \& Herman 1981, Darling \& MCSweeney 1985, Baker et al. 1986, Darling \& Morowitz 1986, Cerchio et al. 1991, 1998), some indicating that movement may not be random. Cerchio et al. (1991, 1998 ) reported that during a season individuals were more likely recaptured off the same island where they were initially captured, and there was evidence of synchronous movement between islands among some individuals. Darling \& Morowitz (1986) suggested that the population off Maui was not identical from year to year as an explanation for the discrepancies between their within-year and across-year estimates. The suggestions of Cerchio et al. $(1991,1998)$ and Darling \& Morowitz (1986) corroborate the findings of the present study and together suggest that movement and distribution among the islands is not random.

Movements of individuals between distant breeding areas introduces a true departure from closure due to 
temporary emigration, since individuals will have a $p_{i}=0$ everywhere in the Hawaiian Islands if they winter in Mexico or Japan. There are 4 published accounts of individuals sighted in consecutive years in Hawaii and Mexico (Darling \& Jurasz 1983, Darling \& McSweeney 1985, Baker et al. 1986), and 1 between Hawail and Japan (Darling \& Cerchio 1993). To my knowledge there are at least 4 additional matches between Hawaii and Mexico (Cerchio \& Jacobsen unpubl, data), and 1. between Hawaii and Japan (D. Salden pers. comm.). Furthermore, the structure of humpback whale songs is very similar and changes in primarily the same ways between Hawaii and Mexico (Winn et al. 1981, Payne \& Guinee 1983, Cerchio 1993) and apparently between Hawaii and Japan (Darling \& Ford 1988, Cerchio pers. obs.). Cross-over between breeding areas has long been thought to be the exception (Baker et al. 1986), but the extent of exchange has yet to be quantified. As sample sizes build and comparisons continue, these long distance movements may still prove to be a significant problem in defining the population.

\section{'Best' estimates, considerations and recommendations}

Due to the inherent biases discussed, the choice of a 'best' estimate from this data set is somewhat problematic; however, the sample size presented here is considerable, and the general range of estimates clearly suggests a revision of the currently accepted abundance estimate for the Hawaiian Islands. Only 1 model produced estimates below 2000 individuals: Chapman's estimate of 1489 individuals from 1989 to 1990 data (Table 3). The validity of this estimate is highly suspect, because it was derived from the smallest samples, was based upon only 4 recaptures, and has a relatively large CV and 95\% confidence interval. Therefore, my results do not agree with the most recent past estimates of Darling \& Morowitz (1986) and Baker \& Herman (1987), and it is apparent that the population is larger than estimated by these studies, regardless of potential biases in this data set. Conversely, the largest estimates, some in excess of 5000 individuals, are likely biased 'high' due to violation of closure assumptions or temporary emigration. It is tempting to choose the model selected by CAPTURE, Chao's $M_{\text {th }}$ of 4858 (95\% CI of 3722 to 6434$)$, as the best estimate, since it incorporates corrections for capture probability varying with sample occasion and due to heterogeneity; however, it is important to consider that this estimate is likely biased positively due to lack of closure, and potentially due to temporary emigration as revealed by the Fisher-Ford analysis. Therefore, I suggest that the abundance of humpback whales in the Hawaiian Islands is likely close to 4000 and almost certainly falls between 3000 and 5000 individuals.

Considering the general range, these estimates may indicate substantial growth of the population since the late 1970 s (Darling \& Morowitz 1986, Baker \& Herman 1987). Determination of population growth and recovery over the past decade depends on 2 factors: the verification of previous estimates and the precise and valid estimation of current abundance. It is highly advisable that data from the late 1970 s and early 1980 s be re-examined for heterogeneity of capture probabilities, and other potential negative biases. Models that allow for variation of capture probabilities may be more appropriate, and may consequently yield higher estimates. Baker \& Herman (1987) state that heterogeneity may exist in their data set, but do not employ models to correct for it. If the population was segregated to some extent, as suggested by Baker and Herman (1981), then the abundance estimates of Baker \& Herman (1987) may be substantially negatively biased. It is probable that even the higher estimate of Darling \& Morowitz (1986) is negatively biased. The rate of discovery method used by Darling \& Morowitz assumes that each sample is independent and every individual in the population has an equal chance of capture with each observation. This is impossible and violation would result in an artificially high number of recaptures and underestimation of abundance.

It is also possible that the estimates presented here are not directly comparable to those of Darling \& Morowitz (1986) and Baker \& Herman (1987). The former studies were conducted primarily off Maui and Hawaii, whereas this study was conducted exclusively off Kauai. Baker \& Herman (1981) suggested that whales off Kauai may represent a semi-isolated subpopulation. Cerchio et al. $(1991,1998)$ found exchange between Kauai and Hawaii, but the exchange did not appear to be completely random. This study suggests that the population off Kauai varies among years and that mixing among the population may not be random. Furthermore, the distribution and movement patterns of individuals may have changed over the intervening decade. Mobley \& Bauer (1991) presented evidence from aerial surveys that both distribution and abundance throughout the Hawaiian Islands changed between 1980 and 1990. It is possible that different biases affected the respective estimates and different portions of the population were sampled.

It is apparent that sampling off 1 island is not completely adequate to accurately estimate abundance. All of the biases associated with non-random mixing are the result of sampling a highly mobile and poorly defined population in a small portion of its range. Only a sampling effort that extends to all areas of whale con- 
centration throughout the Hawaiian Islands can assure a representative sample of the population. This would entail simultaneous effort off the northwest coast of Hawail, the 4 island region off Maui, on Penguin Bank, and off Kauai. Sampling would need to be consistent throughout the entire season to assure equal probability of capture of individuals with temporally staggered residency (Gabriele 1992). Such a sampling regime would clarify the patterns of movement throughout the islands and facilitate the choice or development of appropriate estimation models. Finally, sample size would need to be large enough to draw conclusions concerning population dynamics. Robson \& Regier (1964) recommend an accuracy of 0.5 (confidence limits of $0.5 \mathrm{~N}, 1.5 \mathrm{~N}$ ) for preliminary studies, 0.25 for management work, and 0.1 for studies into population dynamics. An accuracy of 0.1 will require sample sizes of 900 to 1200 per sampling occasion (i.e. year) for a population of 5000 animals, depending on the estimation methods (Robson \& Regier 1964). It seems likely that this endangered population is recovering; however, much more work is required before the extent and rate of the recovery is known.

Acknowledgements. Many individuals were involved in the collection of data for this study. Tom Norris collected many of the photographs and helped direct the field effort in 1991 and 1992. Other photographers and contributors were Dan Shapiro, Thea Jennsen, Gene Kent, Jean Lemire, Tom Kieckhefer, Johanna Slob, Marci Greenberg, Ruth Lewis, Renate Sponer, Ann Zoidis, Tim Cole, Alan Reitsch, Denis Jensen, Peter Duley, Chris Gabriele, Adam Frankel, Jackie Murphy and Chuck Moon. Bernd Würsig provided the initial inspiration for the field work, his guidance, and many loans of equipment. I thank Ken Burnham for his assistance with some of the mark-recapture statistics. John Megahan created the study site figure. The manuscript was improved with thoughtful review by John Calambokidis, Jay Barlow, C. Scott Baker, Jim Harvey, and several anonymous reviewers. Funding was provided by Whale Aid, Earthtrust, the American Cetacean Society-Monterey Bay, Los Angeles and National chapters, the Animal Behavior Society, Sigma Xi, the American Museum of Natural History, the Myers Foundation for Marine Research, and the Packard Foundation. The 1993 field season and data analysis was funded primarily by the ATOC (Acoustic Thermotography of Oceanic Climate) Marine Mammal Research Program under the direction of Ann Bowles and Joe Mobley. The NOAA Sanctuaries and Reserves Division provided support for analysis and writing. Moss Landing Marine Laboratories and its staff provided much needed institutional support. All data collection was conducted under Federal Research Permit no. 663.

\section{LITERATURE CITED}

Alvarez C, Aguayo A, Rueda R, Urbán J (1990) Estimates of humpback whale stock size along the mainland coast of the Mexican Pacific. Rep Int Whal Comm Spec lssue No. 12:191-193

Baker CS, Herman LM (1981) Migration and local movement of humpback whales (Megaptera novaeangliae) through
Hawaiian waters. Can J Zool 59:460-469

Baker CS, Herman LM (1987) Alternative population estimates of humpback whales (Megaptera novaeangliae) in Hawaiian waters. Can J Zool 65:2818-2821

Baker CS, Herman LM, Perry A, Lawton WS, Straley JM, Wolman AA, Kaufman GD, Winn HE, Hall JD, Reinke JM, Östman J (1986) Migratory movement and population structure of humpback whales (Megaptera novaeangliae) in the central and eastern North Pacific. Mar Ecol Prog Ser 31:105- 119

Begon M (1979) Investigating animal abundance: capturerecapture for biologists. University Park Press, Baltimore

Bishop JA, Sheppard PM (1973) An evaluation of two capture-recapture models using the technique of computer simulation. In: Bartlett MS, Hiorns RW (eds) The mathematical theory of the dynamics of biological populations. Academic Press, London

Brown MR, Corkeron PJ, Hale PT, Shultz KW, Bryden MM (1995) Evidence for a sex segregated migration in the humpback whale (Megaptera novaeangliae). Proc R Soc Lond Ser B 259:229-234

Buckland ST (1990) Estimation of survival rates from sightings of individually identifiable whales. Rep Int Whal Comm Spec Issue No. 12:149-153

Calambokidis J, Cubbage JC, Steiger GH, Balcomb KC, Bloedel P (1990) Population estimates of humpback whales in the Gulf of the Farallones, California. Rep Int Whal Comm Spec Issue No 12:325-333

Calambokidis J, Steiger GH, Evenson JR (1993) Photographic identification and abundance estimates of humpback and blue whales off California in 1991-92. Final report to Southwest Fisheries Center, NMFS, Contract 50 ABNF100137

Calambokidis J, Steiger GH, Evenson JR, Flynn KR, Balcomb KC, Claridge DE, Bloedel P, Straley JM, Baker CS, von Ziegesar O, Dahlheim ME, Waite JM, Darling JD, Ellis G, Green GA (1996) Interchange and isolation of humpback whales off California and other North Pacific feeding grounds. Mar Mamm Sci 12:215-226

Calambokidis F, Steiger GH, Straley JN, Quinn T, Herman L, Cherchio S, Salden DR, Yamaguchi M, Sato F, Urban J, Jacobsen J, von Ziegesar O, Balcomb KC, Gabriele CM, Dahlheim ME, Higashi N, Uchida S, Ford JKB, Miyamura $Y$, Ladron P, Mizroch SA, Schlender L, Rasmussen K (1998) Population abundance and structure of humpback whales in the North Pacific Basin. Final report to NMFS, Southwest Fisheries Center, contract no. 50ABNF500113

Carlson CA. Mayo CA, Whitehead H (1990) Changes in the ventral fluke pattern of the humpback whale (Megaptera novaeangliae), and its effect on matching; evaluation of its significance to photo-identification research. Rep Int Whal Comm Spec Issue No 12:325-333

Cerchio S (1993) Geographic variation and cultural evolution in songs of humpback whales (Megaptera novaeangliae) in the eastern North Pacific. MSc thesis, Moss Landing Marine Laboratories and San Jose State University, CA

Cerchio S, Gabriele C, Frankel A (1991) Inter-island movements of humpback. whales in the Hawaiian Islands: three seasons off Kauai and Hawaii. In: Abstracts 9th Biennial Conf Biol Mar Mammals, 1991,Chicago, Illinois, December $5-9$

Cerchio S, Gabriele CM, Norris T, Herman LM (1998) Movements of humpback whales between Kauai and Hawaii: implications on population structure and abundance estimation in the Hawaiian Islands. Mar Ecol Prog Ser $175: 13-22$

Chao A (1989) Estimating population size for sparse data in 
capture-recapture experiments. Biometrics 45:427-438

Chao A, Lee SM, Jeng SL (1992) Estimating population size for capture-recapture data when capture probabilities vary by time and individual animal. Biometrics 48:201-216

Chittleborough RG (1965) Dynamics of two populations of humpback whale, Megaptera novaeangliae (Borowski). Aust J Mar Freshw Res 16:33-128

Darling JD, Cerchio S (1993) Movement of a humpback whale (Megaptera novaeangliae) between Japan and Hawaii. Mar Mamm Sci 9:84-89

Darling JD, Ford JKB (1988) A study of the current status of humpback whales in Japan Progress report, August 1988 Available: World Wide Fund for Nature Japan, Tokyo, or West Coast Whale Research Foundation, Vancouver

Darling JD, Gibson KM, Silber GK (1983) Observations on the abundance and behavior of humpback whales (Megaptera novaeangliae) off West Maui, Hawaii (1977-79). In: Payne $\mathrm{R}$ (ed) Communication and behavior of whales, AAAS Selected Symposia Series. Westview Press, Boulder, p 201-222

Darling JD, Jurasz CM (1983) Migratory destinations of North Pacific humpback whales (Megaptera novaeangliae). In: Payne $R$ (ed) Communication and behavior of whales, AAAS Selected Symposia Series. Westview Press, Boulder, p 359-368

Darling JD, McSweeney DJ (1985) Observations of the migrations of North Pacific humpback whales (Megaptera novaeangliaej. Can J Zool 63:308-314

Darling JD, Mori K (1993) Recent observations of humpback whales in Japanese waters off Ogasawara and Okinawa. Can J Zool 71:325-333

Darling JD, Morowitz H (1986) Census of 'Hawaiian' humpback whales (Megaptera novaeangliae) by individual identification. Can J Zool 64:105-111

Darroch JN (1958) The multiple-recapture census: I. Estimation of a closed population. Biometrika 45:343-359

Dawbin WH (1966) The seasonal migratory cycle of humpback whales. In: Norris KS (ed) Whales, dolphins, and porpoises. University of California Press, Berkeley, p 145-171

Fisher RA, Ford EB (1947) The spread of a gene in natural conditions in a colony of the moth Panaxia dominula (L). Heredity 1:143-174

Gabriele CM (1992) The behavior and residence characteristics of reproductive classes of humpback whales (Megaptera novaeangliae] in the Hawaiian Islands. MSc thesis, University of Hawaii, Honolulu

Hammond PS (1986) Estimating the size of naturally marked whale populations using capture-recapture techniques. Rep Int Whal Comm Spec Issue No. 8:253-282

Hammond PS (1987) Techniques for estimating the size of whale populations. Symp Zool Soc Lond 58:225-245

Hammond PS (1990) Heterogeneity in the Gulf of Maine? Estimating humpback whale population size when capture probabilities are not equal. Rep Int Whaling Comm Spec Issue No. 12:325-333

Herman LM, Antinoja RC (1977) Humpback whales in the Hawaiian breeding waters: population and pod characteristics. Sci Rep Whales Res Inst Tokyo 29:59-85

Katona SK, Beard JA (1990) Population size, migrations and feeding aggregations of the humpback whale (Megaptera novaeangliae) in the western North Atlantic. Rep Int Whaling Comm Spec Issue No, 12:295-305

Katona S, Baxter B, Brazier O, Kraus S, Perkins J, Whitehead $\mathrm{H}$ (1979) Identification of humpback whales by fluke photography. In: Winn HE, Olla BL (eds) Behavior of marine animals, Vol 3. Plenum Press, New York, p 33-44
Manly BFJ (1970) A simulation study of animal population estimation using the capture-recapture method. J Appl Ecol 7:13-39

Mobley JR Jr, Bauer GB (1991). Changes in distribution of humpback whales on the Hawailan wintering grounds: 1990 aerial survey results. In: Abstracts, 9th Biennial Conf Biol Mar Mammals, Chicago, December 5-9, 1991

Otis DL, Burnham KP, White GC, Anderson DR (1978) Statistical inference for capture data on closed animal populations. Wildl Monogr 62:1-135

Palsbøll PJ, Allen J, Bérubé M, Clapham PJ, Feddersen TP, Hammond PS, Hudson RR, Jørgensen $\mathrm{H}$, Katona S, Larsen AH, Larsen F, Lien J, Mattila DK, Sigurjónsson J, Sears R, Smith T, Sponer R, Stevick P and Ølen N (1997) Genetic tagging of humpback whales. Nature 388:767-769

Payne RS, Guinee LN (1983) Humpback whale songs as an indicator of 'stocks' In: Payne R (ed) Communication and behavior of whales, AAAS Selected Symposia Series. Westview Press, Boulder, p 333-358

Perry A, Baker CS, Herman LM (1990) Population characteristics of individually identified humpback whales in the central and eastern North Pacific: a summary and critique. Rep Int Whal Comm Spec Issue No. 12:325-333

Pollock KH (1991) Modeling capture, recapture and removal statistics for estimation of demographic parameters for fish and wildlife populations: past, present, and future. J Am Statist Assoc 86:225-238

Pollock KH, Nichols JD, Hines JE, Brownie C (1990) Statistical interence for capture-recapture experiments. Wildl Monogr 107:1-97

Rice DW (1974) Whales and whale research in the eastern North Pacific In: Schevill WE (ed) The whale problem. Harvard University Press, Cambridge, p 170-195

Rice DW (1978) The humpback whale in the North Pacific: distribution, exploitation and numbers. In: Norris KS, Reeves RS (eds) Report on a workshop on problems related to humpback whales (Megaptera novaeangliae) in Hawaii. Report to the US Marine Mammal Conmission, Washington, DC, p 29-44

Rice DW, Wolman AA (1978) Humpback whales census in Hawaiian waters-February 1977. In: Norris KS, Reeves RS (eds) Report on a workshop on problems related to humpback whales (Megaptera novaeangliae) in Hawaii. Report to the US Marine Mammal Commission, Washington, DC, p 45-53

Rice DW, Wolman AA (1979) Census of humpback whales wintering around the Hawaiian Islands, 1976-1979. Int Whal Comm Co IWC SC/31/Doc 38

Robson DS, Regier HA (1964) Sample size in Petersen markrecapture experiments. Trans Am Fish Soc 93:215-226

Seber GAF (1982) The estimation of animal abundance and related parameters Macmillan Publishing Co, New York

Straley J (1990) Fall and winter occurrence of humpback whales (Megaptera novaeangliae) in southeast Alaska. Rep Int Whal Comm Spec Issue No. 12:319-323

Straley J (1994) Seasonal characteristics of humpback whale (Megaptera novaeangliae) in Alaskan waters. MSc thesis, University of Alaska, Fairbanks

Urbán J, Aguayo A (1987) Spatial and seasonal distribution of the humpback whale, Megaptera novaeangliae, in the Mexican Pacific. Mar Mamm Sci 3:333-344

Winn HE, Thompson TJ, Cummings WC, Hain J, Hudnall J, Hays $H$, Steiner WW (1981) Song of the humpback whale: population comparisons. Behav Ecol Sociobiol 8:41-46

Wolman AA, Jurasz CM (1977) Humpback whales in Hawaii: vessel census, 1976. Mar Fish Rev 39:1-5 